\title{
A preliminary study of the calcification reason of pit mud in Chinese Strong-flavour liquor
}

\author{
Bin CHEN $^{a}$, Deliang WANG ${ }^{a}$, Yinzhuo YAN ${ }^{a}{ }^{a} *$
}

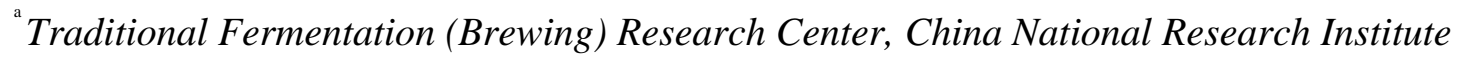

of Food \& Fermentation Industries, Beijing 100015, China

\section{Abstract:}

Pit mud play a key role in the brewing process of Chinese Strong-flavour liquor. In this study, the organic acids and metal ions was determinated by Ion Chromatograph and Inductively Coupled Plasma Mass Spectrometry, respectively. The diversities and structures in pit mud were analyzed by using high-throughput sequencing based on Illumina Miseq platform. The results showed that the lactic acid in calcified pit mud was about 10 times higher than quality pit mud, and the calcium ions was about 20 times higher than quality pit mud. It could found a strange phenomenon, the calcified pit mud had more pyruvic acid and quality pit mud basically does not had this kind of material. The data analysis shown that the pit mud were detected prokaryotes 908 strains and the eukaryotes 226 strains. It was found that the Lactobacillus and Prevotella in calcified pit mud (the total of both increase 11 times) had a higher percentage. It can be guess that the lactic acid and metal ions would form lactic acid salt compounds and those compounds could affect the growth and reproduction of microbes in pit mud. This study provided a good comparison of physical and chemical properties between the calcified pit mud and the quality pit mud, which was significant for the maintenance of pit mud and the quality of liquor. Because of the first study for pit mud by using high-throughput sequencing, it could provide theoretical basis for improving microbes in pit mud.

Key words: Pit mud; Calcification reason; Physical and chemical properties; Microbial structure 


\section{Importance :}

This article introduced the study of pit mud, it found that there were many difference between the calcified pit mud and quality pit mud.

This study provided a good comparison of microbial diversities and structures between the calcified pit mud and the quality pit mud, which was significant for the maintenance of pit mud and improved the quality of liquor.

To the best of our knowledge, this is the first report about the microbial community structure and diversity in calcified pit mud and quality pit mud by using high-throughput sequencing, which will help us to improve the quality of pit mud, solve the problem of calcification and enhance the quality of the Strong-flavor liquor.

\section{Introduction}

Chinese liquor is one of the six most famous distilled alcoholic beverages in the world and is very popular in China. In general, it is mainly classified into the six types: Strong-flavour, Light-flavour, Sauce-flavour, Sesame-flavour, Rice-flavor and other different flavours. The most popular type is Strong -flavour liquor in the market, which was about $70 \%$ of all types (1). It uses pit mud as the fermentation cornerstone, which is a fermenting agent and has a significant impact on the flavour of the product. Therefore, high quality aged pit mud has the reputation of 'National treasure mud' and 'Microbial gold' in China. However, with the increase of pits mud aging, the main question is the calcification, which will leads to the pits mud become more and more rigid and even appear the white crystalline. The crystalline will directly affects the microbial diversities and structures of pit mud. It is a valuable industry resource, but the loss and lack of this resource are also obvious recently. So it is necessary to understand the reason of calcification, especially the imparity of the two types. The study would focus on the research of microbial structure.

Analyzing the structures and diversities of the microbial community has always been a big challenge for Chinese microbiologists. Pit mud quality, according to its sensory characteristics, can be divided into three grades: degraded, normal, and high quality. However, the relationship between pit mud microbial community and pit mud quality is poorly understood (2). In the latest thirty years, most Chinese microbiologists used culture-dependent and culture-independent 
methods to analyze the dominating microbes in pit mud. In 1991, a strain of Clostridium prazmowski was found as the main microorganism in Wuliangye pit mud by the culture-dependent method (3). With the progress in technology, there are many approaches to study the microorganism in the pit mud, such as denaturing gradient gel electrophoresis (DGGE), phospholipids fatty acid (PLFA), High-throughput sequencing. Recently, Clostridiales, Lacotobacillales and Bacillales were reported as the main bacterial microorganisms and Pichia anomala was the main yeast in pit mud by combined DGGE and PLFA analyses (4). Lately, Liang $\mathrm{H}$ et al (5), found that there were some significant differences in the microbial community structure between aged and aging pit mud by the methods of PCR-DGGE and qPCR. Li C et al (6), found clostridium butyricum is an important fragrance-producing bacterium in the traditional Chinese flavor liquor-making industry. But the technology of high-throughput sequencing was not used currently. It was a cost-expensive method for knowing the characterization of pit mud microbial communities, but these analysis methods were very effective. The analysis can get millions of DNA sequence and transcriptome sequencing or genome sequencing. So it is cost-effective for the study of microbial diversities and structures. In this study, Illumina MiSeq platform was used to evaluate the differences in calcified pit mud and quality pit mud. To the best of our knowledge, this is the first report about the microbial community structure and diversity in calcified pit mud and quality pit mud by using high-throughput sequencing.

Through the study of the physical and chemical properties and microbial structure of the two kinds of pit mud, it was found some difference. Hence, the structure and composition of microbes studied by modern science and technology has become a new subject in liquor-making industry, which will help us to understand the pit mud and even solve the problem of calcification or enhance the quality of the Strong-flavour liquor.

\section{Materials and Methods}

\section{Sampling}

In this study, the quality and calcified pit mud samples were collected from Yanghe and shuanggou manufactory, which were located in Jiangsu province in China. S5JD1, S5JB1, S5JD3 and S5JD4Ca were collected from the Shuanggou. They were all quality pit muds, except the last sample. YH1JN, YH11JD, YH11BCad and YH11BCau were collected from the Yanghe. The first 
two were the quality pit muds and the last two were the calcified pit muds. Approximately $20 \mathrm{~g}$ of each sample were transferred to sterile polyethylene bags and stored at $-20{ }^{\circ} \mathrm{C}$ until analyzed.

\section{The determination of organic acids in pit mud}

For the determination of organic acids in pit mud, this experiment adopts ISC3000 ion chromatograph, concrete operation as follows, (1) Take the pit mud $5 \mathrm{~g}$, dissolved in $25 \mathrm{~mL}$ ultrapure water, after fully oscillation, $2000 \mathrm{rpm}$ centrifuge for $10 \mathrm{~min}$. (2) Through $0.45 \mu \mathrm{m}$ water phase membrane to filter and diluted 100 times, then testing by ISC3000 ion chromatograph. Instrument set conditions as follows: pillar type IONPAC ${ }^{\circledR}$ AG11-HC $4 \mathrm{~mm} \times 50 \mathrm{~mm}$, pillar temperature $30^{\circ} \mathrm{C}$, nitrogen pressure $6 \mathrm{kPa}$. In order to guarantee the authenticity of the sample data, it was necessary to every four samples to join a standard sample (the lactic acid concentration $50 \mu \mathrm{g} / \mathrm{L})$.

\section{The determination of metal ions in pit mud}

For the determination of metal ions in pit mud, this experiment adopts NexION 350 Inductively Coupled Plasma Mass Spectrometer (ICP-MS), concrete operation as follows, (1) Take some pit mud, air dry for one week and grinding, then through 200 mesh sieve. (2) Accurate weighing $0.2 \mathrm{~g}$ (Accurate to 0.001 ), then placed in digestion jar, add $4 \mathrm{~mL}$ of nitric acid $\left(\mathrm{HNO}_{3}\right), 2$ $\mathrm{mL} \mathrm{H}_{2} \mathrm{O}_{2}, 2 \mathrm{~mL}$ hydrofluoric acid (HF), finally put the digestion jar to microwave digestion instrument for $1 \mathrm{~h}$. (3) After digestion, add $1 \mathrm{~mL}$ perchloric acid $\left(\mathrm{HClO}_{4}\right)$, then placed on the heating plate, evaporation and take the remaining $1 \mathrm{~mL}$. (4) Digestion jar samples transferred into $50 \mathrm{~mL}$ volumetric flask, then constant volume by $1 \% \mathrm{HNO}_{3}$. (5) With $1 \% \mathrm{HNO}_{3}$ solution diluted 100 times, then testing by ICP-MS.

\section{DNA extraction}

Pit mud samples were washed three times with PBS solutions. The total DNA (prokaryotes and eukaryotes) from each sample was extracted by FastDNA SPIN Kit for Soil (MP Biomedicals, USA). The extraction process should according to the manufacturer's instructions and the total DNA was stored at $-80^{\circ} \mathrm{C}$ until further analysis. DNA concentration and purity were determined by a spectrophotometer (UV-VIS, SHIMADZU, Japan) and finally diluted to $50 \mathrm{ng} / \mu \mathrm{L}(7)$.

\section{PCR amplification}


(8). The fragments of ITS1 region from eukaryotes were amplified using the universal primers ITS1F and ITS1R (9). The PCR system were according the methods of Gerard (10). The conditions of the prokaryote amplification were according the methods of Luo (1). But for the eukaryotes, as follows, initial denaturation of DNA at $95^{\circ} \mathrm{C}$ for $5 \mathrm{~min}$, and 45 cycles of denaturation at $95^{\circ} \mathrm{C}$ for $30 \mathrm{~s}$, then annealing at $50^{\circ} \mathrm{C}$ for $30 \mathrm{~s}$ and extension at $72^{\circ} \mathrm{C}$ for $1 \mathrm{~min}$; at last, a final extension at $72^{\circ} \mathrm{C}$ for $5 \mathrm{~min}$. Following successful amplification (identified by agarose gel electrophoresis), amplicon libraries were sequenced using Illumina MiSeq platform by Novogene Bioinformatics Technology Co. Ltd (Beijing, China).

\section{Data analysis}

Due to the short read lengths and the overlap DNA fragments, FLASH (Fast Length Adjustment of SHort reads) which was a very fast software tool to find the correct overlap between paired-end reads and extend the reads by stitching them together was applied to solve those problem (11). The concrete was merge pairs of reads when the original DNA fragments were shorter than twice the length of reads. Then according to the unique barcode of each sample, the sequencing reads were assigned to each sample (12).

For the part of taxonomy, sequences were analyzed with the QIIME software package (http://qiime.org/) which supports a wide range of microbial community analyses (13) and through making OTU table (14). Sequences were assigned to OTUs at $97 \%$ similarity and also be compared with the Greengenes database (15). The representative sequences were picked for each OTU and used the RDP (Ribosomal Database Project) classifier to assign taxonomic data to each representative sequence (16), in addition to custom Perl scripts to analyze alpha diversity. The alpha diversity was used to determine whether cover all stains (8).

\section{Results}

The pit mud plays an important role in the quality of Strong-flavour liquor. However, at present most manufactories find that the calcification of pit mud appears frequently, which directly affect the quality of liquor. This experiment mainly study physical and chemical 
properties and microbial structure of pit mud. Here were the results.

\section{The organic acids analysis of the two kinds pit mud}

140 Because of the common acid of pit mud and it mainly from organic acid salts, especially the calcified pit mud, so it was necessary to find out what kind of organic acid to make it. Nine kinds of main organic acids were identified, the results were shown in table 1. From the table, it can be found that the highest organic acid was lactic acid in each samples. The lactic acid content of calcified samples (S5JD4Ca、YH11BCau、YH11BCad) was in possession of absolute advantage, the lactic acid in calcified pit mud was about 7 times higher than quality pit mud in Yanghe base, the Shuanggou base was about 11 times. Of course, it could found a strange phenomenon, the calcified pit mud had more pyruvic acid and quality pit mud basically does not had this kind of material. This was very worthy of our thinking.

\section{The metal ions analysis of the two kinds pit mud}

In order to understand more thoroughly of calcification problem, the experiment were tested metal ions of pit mud. Twelve kinds of main organic acids were identified, the specific results were shown in table 2. From the table, calcified pit mud had higher $\mathrm{Ca}, \mathrm{Mg}$ and $\mathrm{Fe}$ metal ions than quality pit mud, shuanggou base content were higher than yanghe base. Through the calculation, it could found that for the yanghe base, the calcium ions, magnesium ions and iron ions of the calcified pit mud was about 17 times, 12 times and 5 times than quality pit mud, respectively. For the shuanggou base, it was about 26 times, 23 times and 107 times, respectively. For the other metal ions, there were no significant difference between the two kinds of pit mud.

\section{DNA gel electrophoresis diagram of pit mud}

Through the gel electrophoresis diagram, the fragment of prokaryotes was $298 \mathrm{bp}$ and the eukaryotes was $603 \mathrm{bp}$, it was consistent with the target segments respectively. So it can speculate that the extracted DNA was effective. The specific results were shown in Fig 1. Extracts of microbial genome as templates, with $16 \mathrm{~s}$ rDNA V4 area and ITS1-2 area as the target, it could be building high throughput sequencing library. Library stripe size around $350 \mathrm{bp}$, in line with expectations. The concentration and purity of the library which detected by the Q -bit and Real 
bioRxiv preprint doi: https://doi.org/10.1101/319996; this version posted May 11, 2018. The copyright holder for this preprint (which was not certified by peer review) is the author/funder, who has granted bioRxiv a license to display the preprint in perpetuity. It is made available under aCC-BY-NC-ND 4.0 International license.

-time PCR can satisfy the requirements of computer.

\section{The OTU result of pit mud and Alpha diversity analysis}

Qualified sequencing libraries (including bacteria and fungi) would be for high-throughput sequencing. From the OTU result (Fig 2), it can be found that the Total Tags of calcified pit mud were less than the quality pit mud obviously which both prokaryote microbes and eukaryotic microbes showed the same trend. Those shown that after the calcification of pit mud, lacking of nutrients and too much harmful metabolites, which would be not conducive to microbial habitat.

Of course, from the Fig 2, it could be found the difference between the prokaryotes and eukaryotes obviously. The former is almost 8 times than the latter. So it could be guess that the main role of microbes in pit mud would be prokaryotes.

In order to detect the reliability and comprehensiveness of data, we made alpha diversity analysis. From the rarefaction curve of Shannon, it can be found that the curves was gradually tends to horizontal line, therefore with the increasing depth of the sample sequence, the number of OTU had reached saturation. Those shown that the depth of sequencing had been basically covered all the microbial species.

\section{The structure analysis of microbial community}

The data analysis shown that the samples were detected prokaryotes 908 strains and the eukaryotes 226 strains. Compared with the quality pit mud, for the yanghe manufactory, the prokaryotes reduced $28.2 \%$ and the eukaryotes reduced $44.3 \%$ in the calcified pit mud. For the shuanggou manufactory, the prokaryotes reduced $44.3 \%$ and the eukaryotes reduced $80.9 \%$. We hypothesized that the calcified phenomenon of shuanggou was more serious than yanghe, which was consistent with the facts. From the top sixteen of prokaryotic microorganisms (Fig 3), it could found that the main prokaryotes genera were Ruminococcaceae, Lactobacillus and Prevotella, but the calcified pit mud had more Lactobacillus or Prevotella, especially yanghe manufactory. For yanghe manufactory, the total proportion of Lactobacillus and Prevotella of quality pit mud and calcified pit mud were $4.5 \%$ and $46.5 \%$, respectively. The study found that even in calcification of pit mud, there were still a lot of Methanocorpusculum, especially the calcification sample of S5JD4Ca. This was very strange, because traditional expert thought only quality aged pit mud had large amounts of methane bacteria (17). 
From the top ten of eukaryotic microorganisms (Fig 4), it could found that the main eukaryotic genera was Trichocomaceae, but the content in calcified pit mud was relatively little. There were also some differences between the shuanggou and yanghe manufactory, it could found the latter contains more rich microorganisms. For shuanggou manufactory, the Trichocomaceae proportion of quality pit mud and calcified pit mud were $16.9 \%$ and $0.7 \%$, respectively. For yanghe manufactory, it were $44.9 \%$ and $14.1 \%$, respectively. So it was the objective reflect that the calcification of shuanggou pit mud was more serious.

\section{Discussion}

Chinese liquor is one of the distilled liquor with global reputation. It is called Chinese culture gem because of its unique traditional fermentation process and a long history of drinking culture. The strong-flavor liquor was occupied about $78 \%$ of the Chinese liquor market. Chinese strong liquor plays an important role in Chinese daily life due to it can warm reception guests. The characteristic flavour-aroma formation in Chinese liquor depends on the fermentation style employed, the fermentation foundation (pit mud) and the strains of microorganisms represented (18). Therefore, understanding the physical and chemical properties and microbial distribution, characteristics and functionality of pit mud is of importance to understand and found the reason of calcification and improve the quality of Chinese strong liquor. Here, we present the first microbiological analysis in pit mud using high-throughput sequencing and the first time to study the reason of calcification comprehensively.

\section{The analysis of physical and chemical properties}

Through the pit mud contrast between yanghe and shuanggou, for the organic acids, the results shown that the calcified pit mud had a huge increase in lactic acid content (increased 7 times and 11times, respectively), especially the shuanggou manufactory. Its content is far more than the normal brewing system. However, in comparison with the two base pit mud, there had not too big difference. For the metal ions, the results shown that the calcified reason of yanghe base pit mud was mainly calcium ions (increased 17 times), the calcified reason of shuanggou base pit mud were mainly iron ions and calcium ions (increased 107 times and 26 times, respectively), the content of iron ions was much higher than other pit mud and higher than the content of calcium ion. Of course the magnesium ions was also the main cause of calcification in pit mud. 
bioRxiv preprint doi: https://doi.org/10.1101/319996; this version posted May 11, 2018. The copyright holder for this preprint (which was not certified by peer review) is the author/funder, who has granted bioRxiv a license to display the preprint in perpetuity. It is made available under aCC-BY-NC-ND 4.0 International license.

By analysing the physical and chemical properties (organic acid and metal ions) of the calcified and quality pit mud, it could found that the calcified pit mud contained more $\mathrm{Fe}^{3+}, \mathrm{Mg}^{2+}$, $\mathrm{Ca}^{2+}$ and lactic acid, so it can be guess that those metal ions will combine with lactic acid and form chemical compounds such as calcium lactate, Iron lactate and magnesium lactate. According to the previous studies, the white crystal of calcified pit mud were ferrous lactate, magnesium lactate and copper lactate (19), which was also consistent with our study. Those compounds will affects the growth of microbes in pit mud. Here noted an interesting phenomenon, the calcified pit mud had more pyruvic acid and quality pit mud basically does not had this kind of material. The pyruvic acid is a key intermediate in cellular metabolic pathways and it mainly from the metabolic process. However, someone found some defects bacteria can produce pyruvic acid, such as Acinetobacter, Enterobacter and Torulopsis (20). So the reason of pyruvic acid appeared in calcified pit mud may be the inbalance of the microbial metabolic process.

\section{The analysis of microbial structure}

Because of the complexity of the pit mud, and it found prokaryotes 908 strains and the eukaryotes 226 strains, it was analyzed the main typical microorganism. So we study the three species (Ruminococcaceae, Lactobacillus and Trichocomaceae). Ruminococcaceae was a thermophilic and cellulolytic microorganism. It usually appeared in the intestinal microbiota which was play an important role in the metabolic processes. Through degraded cellulose it can produce such as carbon dioxide, hydrogen, ethanol, acetate. (21). Lactobacillus was a genus of Gram-positive facultative anaerobic or microaerophilic rod-shaped bacteria. Many Lactobacillus operate using homofermentative metabolism, and some species of Lactobacillus use heterofermentative metabolism. The Lactobacillus can resistant to acid and need very few nutrients to grow (22). Because of the calcified pit mud had the low $\mathrm{pH}$ and the poor nutrition, but the quality pit mud were just the opposite (23) and lactic acid bacteria had lower requirements for environmental. So it can be understand that the calcified pit mud had more Lactobacillus. As a result it could be guess that the main cause of calcification in pit mud were the several stains, especially Lactobacillus, which was consistent with the study of Tao Y (24) in pit mud by denaturing gradient gel electrophoresis (DGGE). As for the Trichocomaceae, it can inhibit certain bacteria breeding, when these fungi decreased (calcified pit mud was reduced by 24 times), it 
bioRxiv preprint doi: https://doi.org/10.1101/319996; this version posted May 11, 2018. The copyright holder for this preprint (which was not certified by peer review) is the author/funder, who has granted bioRxiv a license to display the preprint in perpetuity. It is made available under aCC-BY-NC-ND 4.0 International license.

would lead to excessive breeding of bacteria, even produce large organic acid (25).

At the same time, the study found that even in calcification of pit mud, there were still a lot of methane bacteria. But the traditional industry thought only high quality aged pit mud had large amounts of methane bacteria and it was a characteristic metabolites (17). So our study may be overthrew the former judging and it is worthy of study late.

\section{The speculation of the calcification mechanism}

The rarefaction curve (in this study, which drown by the Shannon curve) were used to evaluate whether the amount of sequencing was enough to cover all taxa and indirectly reflect the species richness in the sample. The rarefaction curve was measured on the 16S rDNA or 18S rDNA sequence that was the relative proportion of known various OTU and calculated the expectations of OTU number when we extracted the reads of the number of $n$ (n was less than the measured total reads sequence), then according to the value of $n$ and the relative expectation, we drawn the rarefaction curve. From the alpha diversity analysis, these results indicated that our study was meaningful and can be represented the true reflection about microbial diversities and structures in calcified pit mud and quality pit mud. So the result was credible and reliant.

\section{The speculation of the calcification mechanism}

Through the result it can be safely drawn the conclusion that the reason of calcification was complex and regional, for example, the calcification of yanghe manufactory was the three kinds of microorganism, especially the Lactobacillus and the Prevotella (in total increased 11 times), it can produce a large number of organic acid, especially the lactic acid, which combined with the excess metal ions, mainly includes calcium ion, magnesium ion and iron ion (the physical and chemical testing: the calcified pit mud were more than 17,12 and 5 times higher than the quality pit mud, respectively), the calcification of shuanggou manufactory was the imbalance of the microbial community and the structure was changed, which made the microbial metabolic disorders. Those imbalance of microbes lead to produce large amounts of lactic acid in pit mud, which combined with the excess metal ions, mainly includes calcium ion, magnesium ion and iron ion (the physical and chemical testing: the calcified pit mud were more than 26, 23 and 107 times higher than the quality pit mud, respectively).

Taken all together, through the physical and chemical properties and using the method of 
high-throughput sequencing, we could get a lot of information between the calcified pit mud and the quality pit mud. It can be guess that the microbial structures of calcified pit mud were out of balance, especially the higher Lactobacillus, and Prevotella and lower Trichocomaceae, it would lead to produce a large amount of lactic acid. Those lactic acid will combine with the redundant metal ions, such as calcium ions, iron ion and magnesium ion, and would form the compounds of lactic acid salt. Those compounds would affect the structure of the microbe. It will be a vicious circle. So in order to ease the calcification phenomenon, it can properly reduce the content of those compounds and inhibit the growth of Lactobacillus and Prevotella, especially the Lactobacillus. These may be an effective method. In order to alleviate or solve the problem of calcification, it can be added a food additive in pit mud to, such as hop acid leaching solution and Nisin, those food additive can inhibit the growth of Lactobacillus effectively. Due to the calcification had a lower $\mathrm{pH}$ value (26), it can adjusted by using the method of adding alkali bacteria and balance the microbial community, in the end it can alleviate the calcification of pit mud. Of course that was only my idea, the feasibility of those measures, it still need to carry on the practice and the effect of these substances would also consider the taste of wine.

To the best of our knowledge, none of the previous studies on the microbial comparison between the calcified and quality pit mud. It was the first system analysis for the calcified pit mud and quality pit mud by using high-throughput sequencing. So it provides an exemplary role for revealing the composition of microbial structure in pit mud. This study also provided a good comparison of physical and chemical properties between the calcified pit mud and the quality pit mud, which was significant for the maintenance of pit mud and the quality of liquor. It was also the first time to explore the reason of calcification in pit mud and provides technical and theoretical support for Chinese strong flavor liquor.

\section{Acknowledgements}

This research was supported by National Natural Science Foundation of China (31401680).

\section{References}

1. Luo Q, et al. (2014). Monitoring of the prokaryotic diversity in pit mud from a Luzhou-flavour liquor distillery and evaluation of two predominant archaea using qPCR assays, Institute of 
bioRxiv preprint doi: https://doi.org/10.1101/319996; this version posted May 11, 2018. The copyright holder for this preprint (which was not certified by peer review) is the author/funder, who has granted bioRxiv a license to display the preprint in perpetuity. It is made available under aCC-BY-NC-ND 4.0 International license.

Brewing \& Distilling, 3, 253-261.

2. $\mathrm{Hu} \mathrm{X}, \mathrm{Du} \mathrm{H}, \mathrm{Ren} \mathrm{C}$, et al. (2016). Illuminating Anaerobic Microbial Community and Cooccurrence Patterns across a Quality Gradient in Chinese Liquor Fermentation Pit Muds. Applied \& Environmental Microbiology, 8, 2506-2515.

3. Wu Y, et al. (1991). Institute of Science and Technology Wuliangye Plant, Acta Microbiologica Sinica, 4, 299-307.

4. Zheng J, Liang R, Zhang L, Wu C, Zhou R, Liao X. (2013). Characterization of microbial communities in strong aromatic liquor fermentation pit muds of different ages assessed by combined DGGE and PLFA analyses, Food Research International, 54, 660-666.

5. Liang H, Luo Q, Zhang A, et al. (2016). Comparison of bacterial community in matured and degenerated pit mud from Chinese Luzhou-flavour liquor distillery in different regions. Journal of the Institute of Brewing, 1, 48-54.

6. Li C, Wang Y, Xie G, et al. (2016). Complete genome sequence of Clostridium butyricum JKY6D1 isolated from the pit mud of a Chinese flavor liquor-making factory. Journal of Biotechnology, 220, 23-24.

7. Yan Y, et al. (2013). Microbial diversity and dynamics of microbial communities during back-slop soaking of soybeans as determined by PCR-DGGE and molecular cloning, World J Microbiol Biotechnol, 29, 1969-1974.

8. Caporaso, J. G., Lauber, C. L., Walters, W. A., Berg-Lyons, D., Lozupone, C. A., Turnbaugh, P. J., Fierer, N. and Knight, R. (2011). Global patterns of 16S rRNA diversity at a depth of millions of sequences per sample, Proc Natl Acad Sci USA, 1, 4516-4522.

9. Op De Beeck, M., Lievens, B., Busschaert, P., Declerck, S., Vangronsveld, J. and Colpaert, J. (2014). Comparison and validation of some its primer pairs useful for fungal metabarcoding studies, PLoS One e97629, 1-11.

10. Gerard Muyzer, et al. (1993). Profiling of Complex Microbial Populations by Denaturing Gradient Gel Electrophoresis Analysis of Polymerase Chain Reaction-Amplified Genes Coding for 16S rRNA, Applied and Environmental Microbiology, 3, 695-700.

11. Magoč, T. and S.L. Salzberg. (2011). FLASH: fast length adjustment of short reads to improve genome assemblies. Bioinformatics, 21, 2957-2963. 
bioRxiv preprint doi: https://doi.org/10.1101/319996; this version posted May 11,2018. The copyright holder for this preprint (which was not certified by peer review) is the author/funder, who has granted bioRxiv a license to display the preprint in perpetuity. It is made available under aCC-BY-NC-ND 4.0 International license.

12. Wang L, Wang Y, Wang H, et al. (2015). Microbial Composition of Bottom Pit Mud in Jiangxiang Baijiu(Liquor) Pit. Liquor-Making Science \& Technology, 1, 12-15.

13. Caporaso, J.G, et al. (2010). QIIME allows analysis of high-throughput community sequencing data. Nat Meth, 5, 335-336.

14. Edgar, R.C. (2013). UPARSE: highly accurate OTU sequences from microbial amplicon reads, Nat Meth, 10, 996-998.

15. DeSantis TZ Jr, et al. (2006). NAST: a multiple sequence alignment server for comparative analysis of 16S rRNA genes, Nucleic Acids Res, 34, W394-W399.

16. Wang, Q, et al. (2007). Naïve Bayesian Classifier for Rapid Assignment of rRNA Sequences into the New Bacterial Taxonomy, Applied and Environmental Microbiology, 16, 5261-5267.

17. Wu Yanyong, liu guangye. (1988). Methane bacteria and luzhou-flavor follows in pit mud, Journal of wine, 2, 29-32.

18. Sun, S.Y., Jiang, W.G., Zhao, Y.P. (2010). Profile of Volatile Compounds in 12 Chinese Soy Sauces Produced by a High-Salt-Diluted State Fermentation. Journal of the Institute of Brewing, 116, 316-328.

19. Zhang Jiaqing, Song Ruibin, Cao Jinghua, et al. (2014). Preliminary analysis of the pit mud crystal in artificial old cellar. China Brewing, 3, 21-23.

20. Li Y, Chen J, Liang D F, et al. (2000). Effect of nutritional conditions on the fermentative production of pyruvic acid by Torulopsis glabrata. Chinese Journal of Biotechnology, 2, $225-228$.

21. Daniela E. Koeck, et al. (2014). Complete genome sequence of the cellulolytic thermophile Ruminoclostridium cellulosi wild-type strain DG5 isolated from a thermophilic biogas plant, Journal of Biotechnology, 188, 136-137.

22. Yang Y G, Huang J X, Rong L I. (2014). Study on screening and growth characteristics of lactic acid bacteria with acid resistant ability, Science \& Technology of Food Industry, 10, 248-251.

23. Sanduo W U, Lai D, Wen K, et al. (2014). Study on the Reasons for Pit Mud Degradation in North China and the Maintenance of pit Mud, Liquor-Making Science \& Technology, 09, $71-74$ 
24. Tao Y, Zhancheng X U, Dongxun L I, et al. (2011). Succession of Bacterial Community in Pit Mud and Its Correlations with Environmental Factors, Liquor-Making Science \& Technology, $9,42-46$

25. Malloch D. (1986). The Trichocomaceae: Relationships with Other Ascomycetes[M] Advances in Penicillium and Aspergillus Systematics. Springer US, 365-382.

26. Li Zuming, S Liu, L Wang, et al. (2011). Physiochemical compositions in pit mud of Deshan Daqu liquor. China Brewing, 12, 110-113.

\section{Table captions:}

Table1 Comparison of main organic acid ion contents in different pit muds

Table2 Comparison of main metal ions contents in different pit muds

\section{Figure captions:}

Fig. 1 A: The gel electrophoresis diagram of the prokaryotes

Fig. 1 B: The gel electrophoresis diagram of the eukaryotes

Fig. 2: The OTU result of pit mud

Fig. 3: The relative proportions of different prokaryotic microorganisms in different pit muds

Fig. 4: The relative proportions of different eukaryotic microorganisms in different pit muds

(1) 
Table1 Comparison of main 1 organic acid ion contents in different pit muds

407

\begin{tabular}{cccccccccc}
\hline Sample & $\begin{array}{c}\text { Lactic } \\
\text { acid }\end{array}$ & $\begin{array}{c}\text { Acetic } \\
\text { acid }\end{array}$ & $\begin{array}{c}\text { Formic } \\
\text { acid }\end{array}$ & $\begin{array}{c}\text { Propionic } \\
\text { acid }\end{array}$ & $\begin{array}{c}\text { Isobutyric } \\
\text { acid }\end{array}$ & $\begin{array}{c}\text { Butyric } \\
\text { acid }\end{array}$ & $\begin{array}{c}\text { Pentanoic } \\
\text { acid }\end{array}$ & $\begin{array}{c}\text { Caproic } \\
\text { acid }\end{array}$ & $\begin{array}{c}\text { Pyruvic } \\
\text { acid }\end{array}$ \\
\hline S5JD1 & 43.21 & 2.89 & 1.24 & 0.46 & 0.2 & 0.33 & 0.53 & 5.84 & 0.12 \\
S5JB1 & 34.62 & 2.12 & 0.89 & 0.49 & 0.88 & 0.16 & 0.24 & 4.91 & 0.24 \\
S5JD3 & 50.16 & 3.76 & 0.39 & 0.25 & 0.35 & 0.43 & 0.18 & 2.54 & 0.18 \\
S5JD4Ca & 477.28 & 2.14 & 0.35. & 0.35 & 0.52 & 0.23 & 0.28 & 4.68 & 30.35 \\
YH1JN & 25.49 & 3.21 & 0.72 & 0.48 & 0.69 & 0.42 & 0.2 & 10.53 & 0.16 \\
YH11JD & 33.17 & 2.42 & 1.02 & 0.31 & 0.64 & 0.65 & 0.47 & 15.26 & 0.32 \\
YH11BCad & 190.01 & 5.19 & 0.87 & 0.43 & 0.57 & 0.59 & 0.51 & 4.67 & 20.23 \\
YH11BCau & 182.16 & 3.26 & 0.48 & 0.32 & 0.49 & 0.83 & 0.24 & 5.29 & 25.35 \\
\hline
\end{tabular}

408

409 Table2 Comparison of main metal ions contents in different pit muds

410

\begin{tabular}{ccccccccccccc}
\hline Sample & $\mathrm{Ba}$ & $\mathrm{Ca}$ & $\mathrm{Mn}$ & $\mathrm{Mg}$ & $\mathrm{Na}$ & $\mathrm{Al}$ & $\mathrm{Zn}$ & $\mathrm{K}$ & $\mathrm{Fe}$ & $\mathrm{Cu}$ & $\mathrm{P}$ & $\mathrm{Pb}$ \\
\hline S5JD1 & 0.42 & 1.49 & 0.35 & 1.03 & 12.04 & 51.72 & 0.04 & 44.7 & 0.73 & 0.04 & 0.19 & 0.02 \\
S5JB1 & 0.45 & 1.67 & 0.33 & 1.06 & 12.11 & 54.18 & 0.03 & 35.67 & 0.78 & 0.03 & 0.3 & 0.02 \\
S5JD3 & 0.28 & 1.59 & 0.5 & 1.98 & 16.03 & 44.11 & 0.04 & 47.96 & 0.6 & 0.04 & 0.19 & 0.02 \\
S5JD4Ca & 0.46 & 39.28 & 0.3 & 24.25 & 11.71 & 40.73 & 0.04 & 36.61 & 75.6 & 0.04 & 0.32 & 0.02 \\
YH1JN & 0.39 & 1.32 & 0.6 & 1.26 & 14.49 & 54.7 & 0.04 & 52.64 & 0.88 & 0.04 & 0.39 & 0.03 \\
YH11JD & 0.23 & 1.92 & 0.42 & 1.5 & 14.53 & 35.67 & 0.05 & 48.13 & 0.94 & 0.05 & 0.29 & 0.02 \\
YH11BCad & 0.42 & 17.43 & 0.57 & 14.98 & 10.78 & 47.96 & 0.04 & 36.41 & 4.19 & 0.05 & 0.22 & 0.02 \\
YH11BCau & 0.42 & 16.54 & 0.48 & 12.22 & 12.78 & 36.61 & 0.06 & 52.03 & 5.58 & 0.04 & 0.41 & 0.02 \\
\hline
\end{tabular}


bioRxiv preprint doi: https://doi.org/10.1101/319996; this version posted May 11, 2018. The copyright holder for this preprint (which was not certified by peer review) is the author/funder, who has granted bioRxiv a license to display the preprint in perpetuity. It is made available under aCC-BY-NC-ND 4.0 International license.

\section{Figure}

434

435

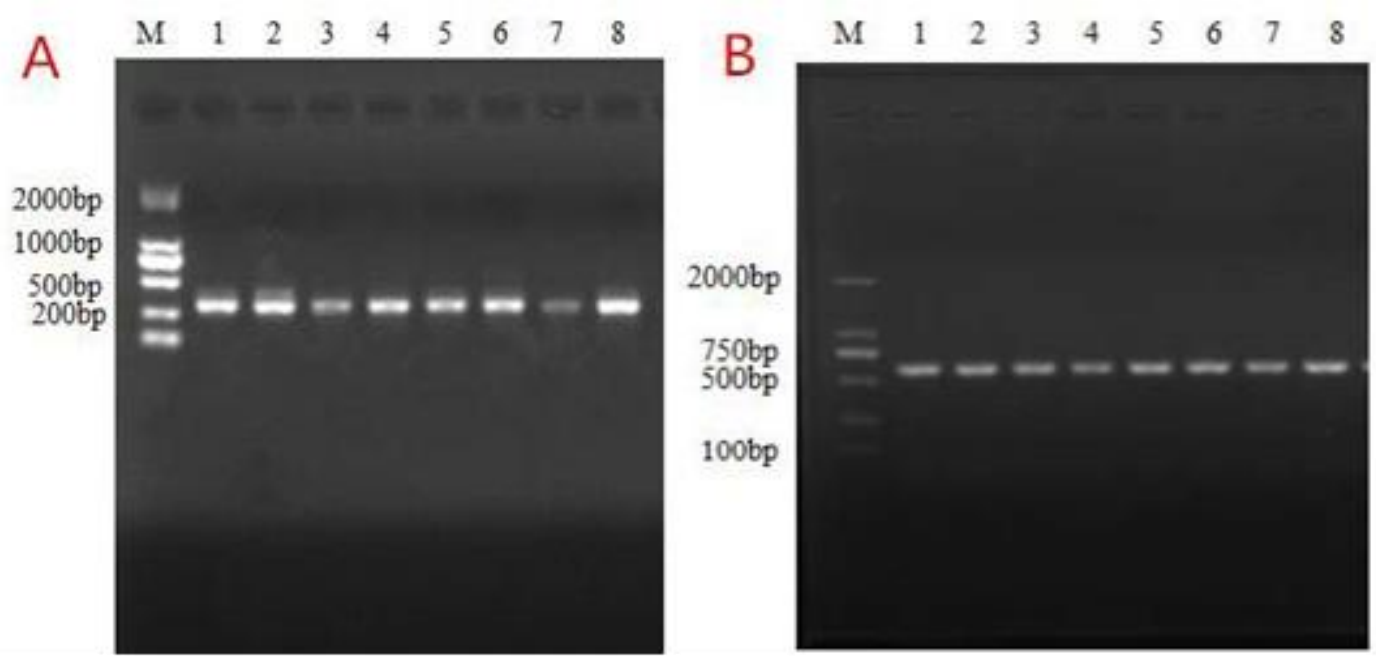

Fig. 1 A: The gel electrophoresis diagram of the prokaryotes. Fig. 1 B: The gel

electrophoresis diagram of the eukaryotes. (Note: M: D2000 mark; 1: S5JD1; 2: S5JB1; 3:S5JD4Ca; 4: S5JD3; 5: YH1JN; 6:YH11JD; 7: YH11BCad; 8: YH11BCau) 


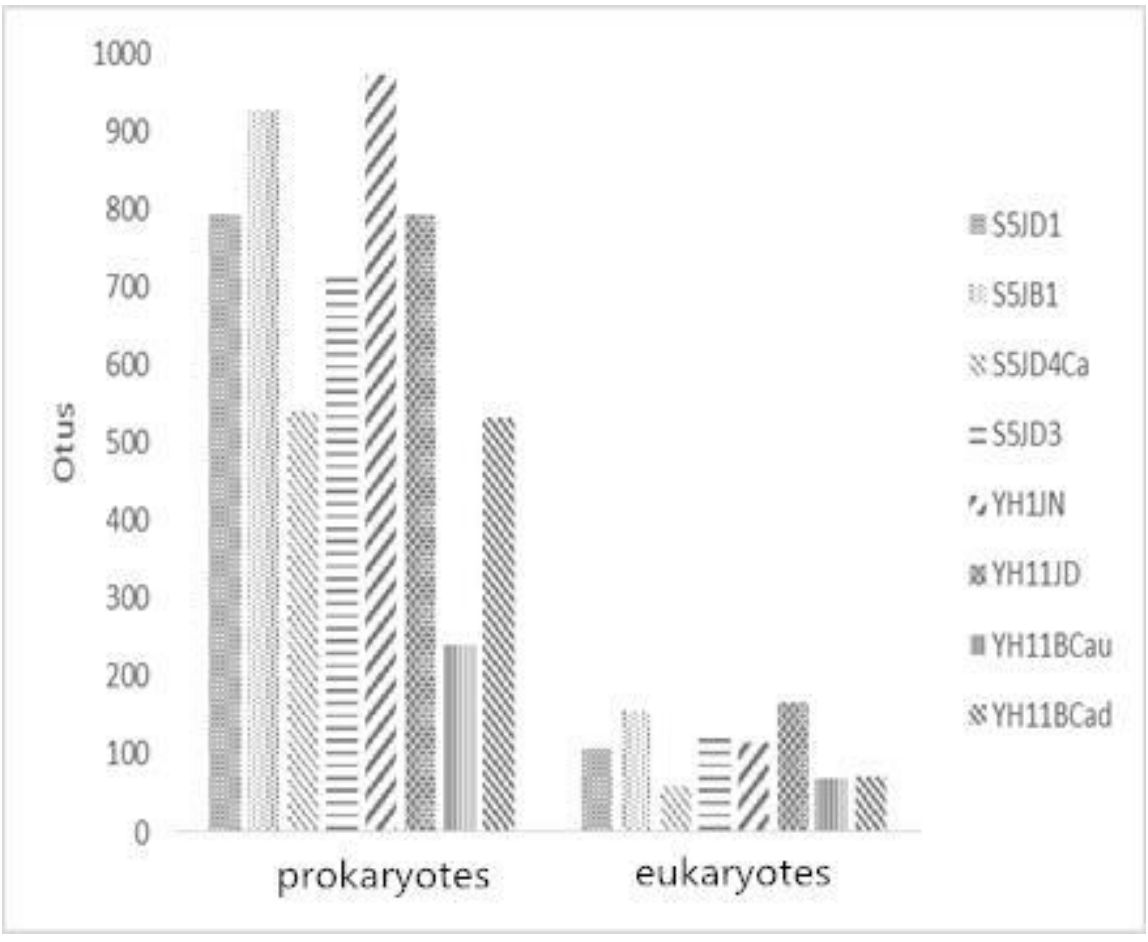

Fig. 2 The OTU result of pit mud

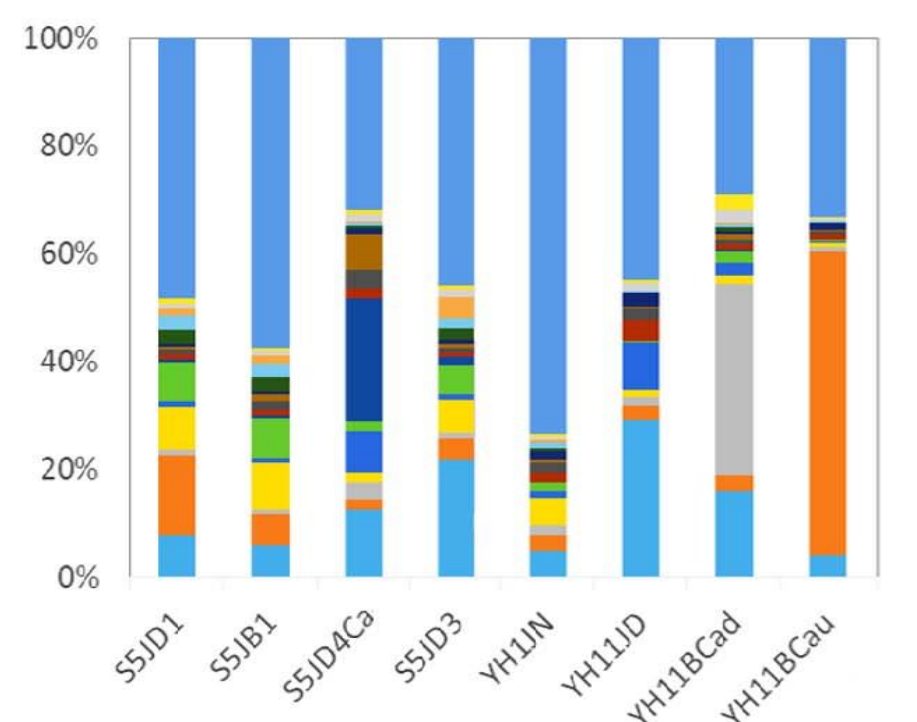

- f_Ruminococcaceae

g_Lactobacillus

g_Prevotella

in_Comamonadaceae

- f_Porphyromonadaceae

m_Halomonas

-g_Methanocorpusculum

g_Syntrophomonas

- o_Bacteroidales

g_Bacteroides

- c_Clostridia

- g_Shewanella

E_Acinetobacter

10_Streptophyta

g_Ruminococcus

o_Clostridiales

others

Fig. 3 The relative proportions of different prokaryotic microorganisms in different pit muds 
bioRxiv preprint doi: https://doi.org/10.1101/319996; this version posted May 11, 2018. The copyright holder for this preprint (which was not certified by peer review) is the author/funder, who has granted bioRxiv a license to display the preprint in perpetuity. It is made available under aCC-BY-NC-ND 4.0 International license.

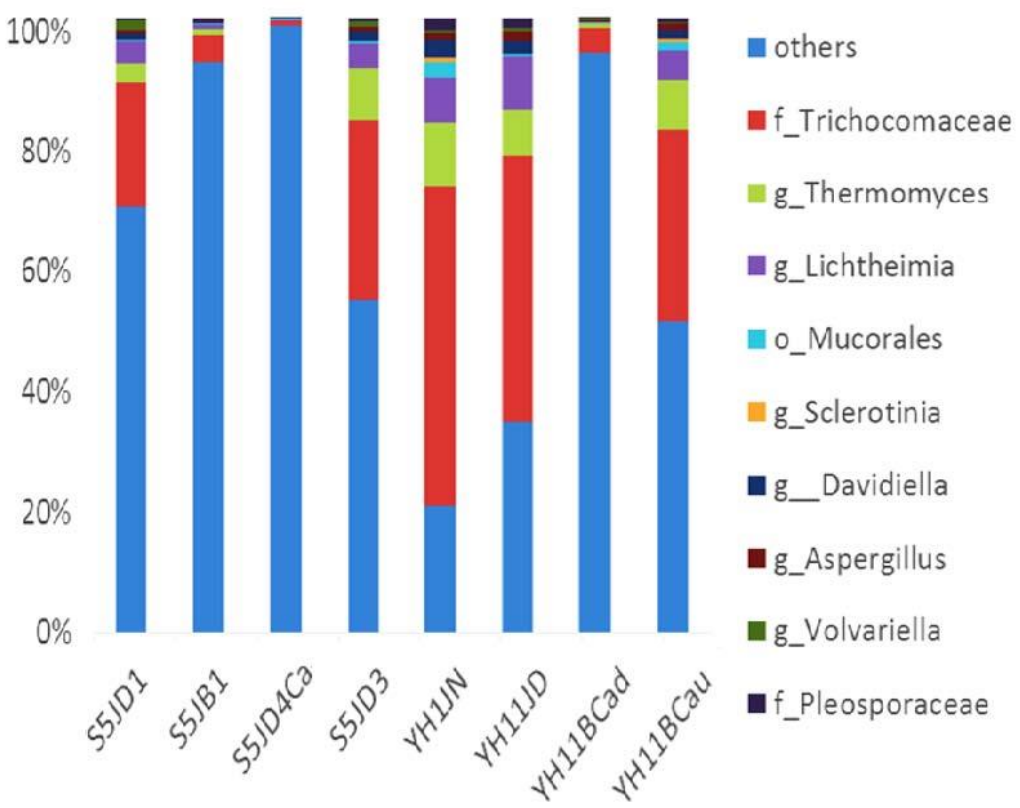

Fig. 4 The relative proportions of different eukaryotic microorganisms in different pit 460 muds 